\title{
Probable biofilm formation in the cheek as a complication of soft tissue filler resulting from improper endodontic treatment of tooth 16
}

This article was published in the following Dove Press journal:

International Journal of Nanomedicine

13 March 2012

Number of times this article has been viewed

\section{Wojciech Marusza' \\ Grazyna Mlynarczyk ${ }^{2}$ \\ Romuald Olszanski ${ }^{3}$ \\ Irina Netsvyetayeva ${ }^{2}$ \\ Michael Obrowski' \\ Tommaso lannitti ${ }^{4}$ \\ Beniamino Palmieri ${ }^{5}$ \\ 'Academy of Face Sculpturing, ${ }^{2}$ Department of Microbiology, Medical University of Warsaw, ${ }^{3}$ Military Institute of Health Services, Warsaw, Poland; ${ }^{4}$ Department of Physiology, School of Medicine, University of Kentucky Medical Center, KY, USA; ${ }^{5}$ Department of General Surgery and Surgical Specialties, University of Modena and Reggio Emilia Medical School, Surgical Clinic, Modena, Italy}

Correspondence: Tommaso lannitti Department of Physiology, School of Medicine, University of Kentucky Medical Center, Lexington, KY 40536-0298, USA $\mathrm{Tel}+3932828|33| 4$

Email tommaso.iannitti@gmail.com

\begin{abstract}
Injectable filling agents offer the promise of a better appearance without surgery and, among them, hyaluronic acid is the most commonly used. Although complications are rare, it is necessary to know the possible side effects and complications in order to be prepared for their management. That is why many researchers have been focusing on the interactions between hyaluronic acid and pathogens, inflammatory mediators, the immune system, and markers of oxidative stress to achieve efficient drug delivery, given that hyaluronic acid has widening applications in the field of nanomedicine. Here we report the case of a 37 -year-old female patient who returned to our clinic with an abscess in her left cheek 3 months after a deep injection of $1 \mathrm{~mL}$ of stabilized hyaluronic acid in both cheeks. Steroid and antibiotic therapy was initiated without success, and abscess drainage was performed. Extraction of tooth 16 was performed 11 days after insertion of drains into the abscess. Laboratory blood tests showed acute inflammation of presumed bacterial etiology. Microbiological examination of pus was negative. Bacterial cultures were found in the extracted tooth. After antibiotic therapy, a complete reversal of the pathological process was observed. The present report highlights the need to assess periodontal problems prior to any aesthetic facial treatment. Analyses of further case reports and clinical studies are necessary to understand the potential role of hyaluronic acid in the formation of biofilm, and how to avoid this complication, thereby increasing the safety of hyaluronic acid-based procedures.
\end{abstract}

Keywords: pantomogram, biofilm, hyaluronic acid, fluorescent in situ hybridization, peptide nucleic acids

\section{Introduction}

For a lot of patients who are seeking facial rejuvenation, injectable filling agents show great promise to improve somebody's appearance without surgery. According to the American Society of Aesthetic Plastic Surgery, it has been recently reported that more than 5 million procedures have been performed using cosmetic injectable compounds, and more than $85 \%$ of all dermal filler procedures have been based on a hyaluronic acid-derived filler. ${ }^{1}$ Hyaluronic acid is a nonsulfated, naturally occurring glycosaminoglycan with a structure consisting of alternately repeating D-glucuronic acid and $\mathrm{N}$-acetylglucosamine units found in several tissues, with the highest concentration occurring in humans in the extracellular matrix of soft connective tissue. ${ }^{2}$ In the hands of experienced physicians, hyaluronic acid can be safely used as a filler, although complications, such as bruising and necrosis, may occur and need to be managed promptly. ${ }^{3,4}$ Although the procedures can be generally considered simple and safe, it is important that, because of the widespread clinical use of hyaluronic acid-based 
fillers, physicians performing these procedures consider the possible consequences and are prepared for their management. ${ }^{5}$ For example, prior to facial rejuvenation procedures, no dental pantomograms are performed. Further, even if the risk of bacterial biofilm development on the injected filling agent and virulence are rare, these potential complications must be taken into consideration. ${ }^{6}$ This report describes a rare case of bacterial biofilm formation on hyaluronic acid filler deeply injected into the cheeks, probably spread from improper endodontic treatment of tooth 16 (first molar).

\section{Hyaluronic acid and nanomedicine}

Hyaluronic acid has been extensively studied in relation to markers of inflammation, oxidative stress, and immune system because it has applications not only in aesthetic medicine, but also in other clinical fields, including ophthalmology, traumatology, urology, and nanomedicine. ${ }^{7}$ Especially with regard to the latter, hyaluronic acid has been used for drug delivery and therefore it has become of key importance to understand its relationship to pathogens and to study its effect on inflammatory mediators, the immune system, and markers of oxidative stress. For instance, hyaluronic acid has been used to transport chemotherapeutic drugs. ${ }^{8}$ It has been shown to be useful when administered intraperitoneally for improving the effects of paclitaxel in gastric cancer. ${ }^{9}$ Furthermore, an experimental study of hyaluronic acid-conjugated butyric acid has showed rapid cellular uptake in a human breast carcinoma cell line. ${ }^{10}$ Another example of the use of hyaluronic acid, to target cells and tissues delivering peptides, comes from a study using hybrid nanoparticles containing hyaluronic acid and iron oxide which showed high efficiency due to highly specific targeting of CD44, a hyaluronic acid binding receptor found on the surface of tumor cells and inflammatory cells. ${ }^{11}$ In the field of ocular drug delivery, hyaluronic acid has been used to modify chitosan nanoparticles, indicating that it might enhance their mucoadhesiveness and efficiency. ${ }^{12}$

With regard to the effect of hyaluronic acid on inflammatory mediators, immune cells, and oxidative stress, it has been observed that hyaluronic acid produces a low-grade inflammatory response when it stimulates peripheral blood mononuclear cells. ${ }^{13}$ The same study also showed a slight increase in the production of interferon- $\gamma$ and higher expression of CD25, CD69, and CD71 in phytohemagglutininstimulated peripheral blood mononuclear cells from patients who underwent hyaluronic acid filler injections and displayed adverse effects.
As far as oxidative stress is concerned, another study investigated the role of chitotriosidase, YKL-40 (a member of the chitinase-like proteins), and myeloperoxidase in inflammatory adverse reactions related to dermal fillers in 169 users in order to understand their relationship with the development of clinical symptoms. ${ }^{14}$ This study showed: (1) a significant rise in circulating myeloperoxidase protein levels associated with more severe adverse reactions in dermal filler users in the absence of infection which was linked to an increased inflammatory interaction, augmented adhesion of circulating leukocytes to vascular endothelial cells and endothelial dysfunction; (2) elevated plasma chitotriosidase activity in the majority of dermal filler users, particularly those with adverse reactions, underscoring a greater activity of monocytes/macrophages in these patients; (3) an increase in plasma YKL-40 expression in dermal filler users with or without clinical adverse reactions; (4) a significant increase in plasma fluorescent lipid peroxidation products (an indirect measurement of macromolecular peroxidation) in dermal filler users with and without adverse reactions; (5) a significant increase in concentrations of advanced oxidation protein products (a marker of oxidative damage to proteins) that were similarly increased in filler users with and without adverse reactions, as compared with controls. ${ }^{14}$

With regard to the relationship between hyaluronic acid and pathogens, we have recently reported an analysis of the interactions between hyaluronic acid and viruses, bacteria, and fungal species. For instance, hyaluronic acid inhibits coxsackievirus B5 (COXB5), mumps virus (MV) and influenza virus strain WSN33 (A/H1N1), herpes simplex virus type 1 and porcine parvovirus (PPV), while it exerts no activity against adenovirus-5 (ADV-5), human herpes virus-6 (HHV-6), and porcine reproductive and respiratory syndrome virus (PRRSV). ${ }^{15}$ In terms of bacterial and fungal species, staphylococci, enterococci, Streptococcus mutans, two Escherichia coli strains, Pseudomonas aeruginosa, Candida glabrata, and Candida parapsilosis exhibit hyaluronic acid dose-dependent growth inhibition, while E. coli ATCC 13768 and Candida albicans do not exhibit any effect, and Streptococcus sanguinis is favored by high hyaluronic acid dose. ${ }^{16}$ In summary, hyaluronic acid produces changes in the immune system, inflammatory mediators, and markers of oxidative stress, and may interact with pathogens. This evidence should be taken into account when performing hyaluronic acid-based delivery of drugs and medical procedures in clinical practice. 


\section{Case report}

A 37-year-old woman required correction of flattened cheeks as a result of aging. After discussing a variety of treatment options with the patient, we decided to utilize an injectable deep subdermal hyaluronic acid filler. The patient signed her informed consent. The procedure was performed at our aesthetic clinic (Academy of Face Sculpturing, Warsaw, Poland). The patient was in excellent health and her endodontic condition was good, as assessed by objective examination. No chronic diseases were reported, and she did not report taking any medicines. The patient had had an orthodontic appliance installed several months prior to the procedure without any reported problems. A lidocaineprilocaine anesthetic cream was applied to the external cheek area prior to the procedure. Her skin was disinfected according to surgical standards. A total of $1 \mathrm{~mL}$ of hyaluronic acid (Restylane ${ }^{\circledR}$ SubQ; Q-Med, Poland) was injected into each cheek via a 23-gauge needle introduced at the apex of the zygomatic arch directed towards her orbicularis oculi and zygomaticus muscles. Treatment also included administration of $1 \mathrm{~mL}$ of hyaluronic acid (Restylane; Q-Med) into both her nasolabial folds and $1 \mathrm{~mL}$ of hyaluronic acid (Restylane Lipp; Q-Med) into her lips in the area of the vermillion border and orbicularis oris muscles in order to improve their appearance. The patient tolerated the procedure well and was satisfied with the results. She was advised to call the clinic if any problem occurred.

Three months later, the patient returned to the clinic because of a firm swelling, approximately $2 \mathrm{~cm}$ in diameter, in the area of the left zygomatic arch. Antibiotic therapy was started (clindamycin $300 \mathrm{mg}$, four times per day) along with prednisone (Encorton ${ }^{\circledR} 20 \mathrm{mg}$, once a day). Three weeks of treatment failed to produce an improvement in the patient's condition. The inflammatory process caused an increase in swelling, resulting in accumulation of an unknown fluid which was mobile and ballotable with increased tension in her skin (Figure 1). Laboratory blood tests (Table 1) showed results consistent with acute inflammation of bacterial etiology, and no signs of an allergic reaction were present (Table 1). Intraoral incision and drainage of a cheek abscess was performed, with intraoral drains placed to allow drainage of abundant purulent discharge. The pus was sent for microbiological tests (with clinical material analysis and microbiological identification of aerobic bacteria, anaerobic bacteria, and yeast-like fungi performed in accordance with standard laboratory procedures recommended by the Clinical

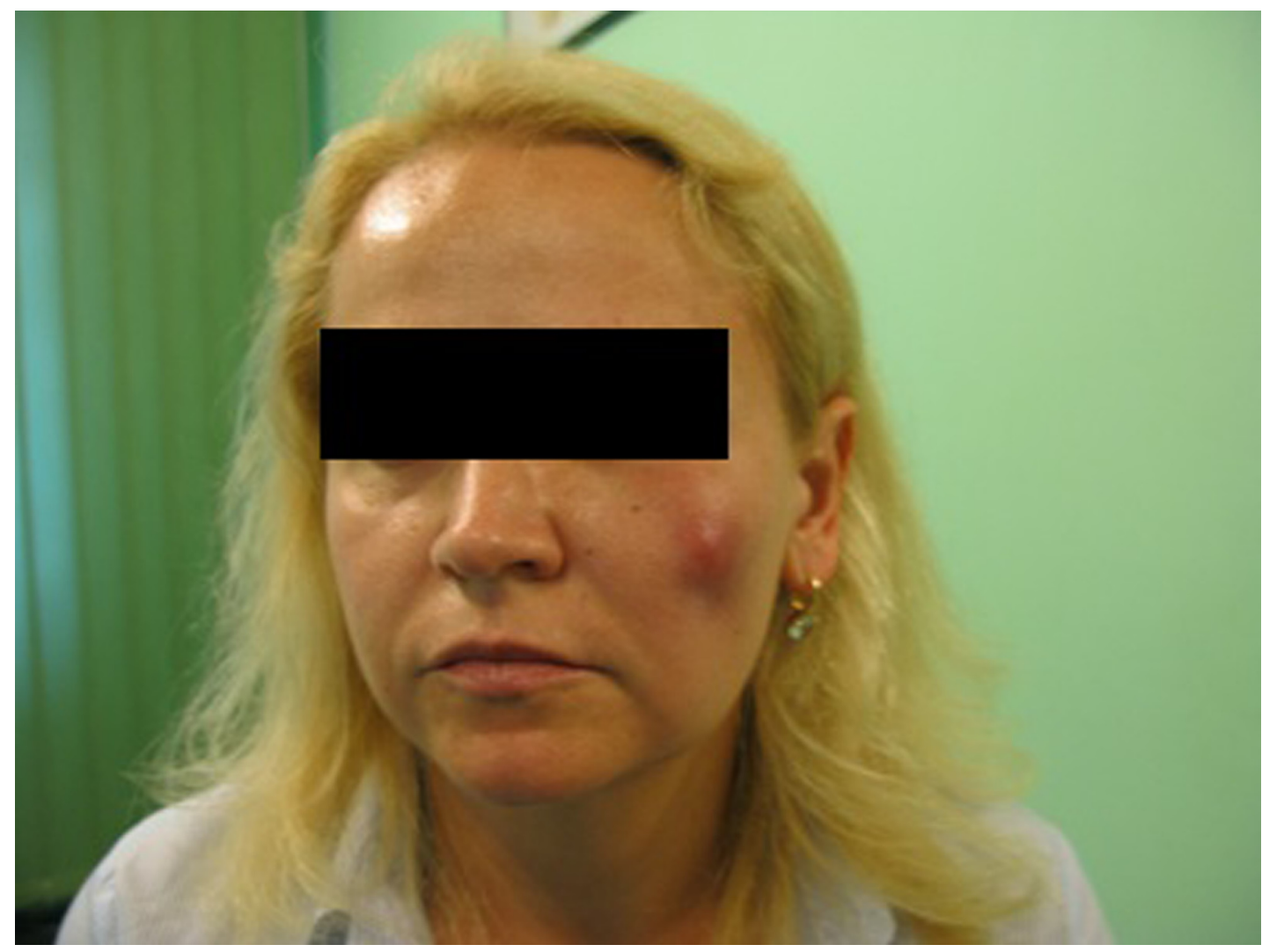

Figure I Swelling resulting from accumulation of fluid within the skin. 
Table I Patient's clinical profile

\begin{tabular}{lll}
\hline Test & Result & Clinical reference \\
\hline White blood cells & 13.1 & $4-1 \mathrm{I} I 0 \% / \mathrm{L}$ \\
Neutrophils & 82.8 & $50 \%-66 \%$ \\
Lymphocytes & 12.6 & $20 \%-40 \%$ \\
Eosinophils & 0.7 & $0 \%-7 \%$ \\
CRP & 11,5 & $<10 \mathrm{mg} / \mathrm{L}$ \\
SD & $1 \mathrm{I}$ & $<12 \mathrm{~mm} / \mathrm{hour}$ \\
IgM & 103 & $40-240 \mathrm{mg} / \mathrm{dL}$ \\
IgG & 1039 & $700-1600 \mathrm{mg} / \mathrm{dL}$ \\
IgE (Total) & 19.6 & $0-120 \mathrm{IU} / \mathrm{mL}$ \\
Total protein & 7.8 & $6.2-8.2 \mathrm{~g} / \mathrm{dL}$ \\
TSH & 0.432 & $0.27-4.2 \mu \mathrm{LU} / \mathrm{mL}$ \\
Free T4 & 15.4 & $12-22 \mathrm{pmol} / \mathrm{L}$ \\
Free T3 & 5.2 & $3.1-6.8 \mathrm{pmol} / \mathrm{L}$ \\
Fibrinogen & 488 & $200-400 \mathrm{mg} / \mathrm{dL}$ \\
D-dimers & 807 & $0-500 \mathrm{ng} / \mathrm{mL}$ \\
Anti-streptolysin O & $<200$ & $<200 \mathrm{IU} / \mathrm{mL}$ \\
Aspartate aminotransferase & 25 & $5-40 \mathrm{U} / \mathrm{L}$ \\
Alanine aminotransferase & 20 & $7-56 \mathrm{U} / \mathrm{L}$ \\
\hline & &
\end{tabular}

and Laboratory Standards Institute). Biochemical identification of microorganisms and antimicrobial susceptibility tests were performed using the Vitek 2 system (BioMerieux, Basingstoke, Hampshire, UK). Computerized tomography and dental pantomography (Kodak 9000 C 3D) were performed and indicated possible spreading of bacterial process from improper endodontic treatment of tooth 16 (Figure 2). Antibiotic treatment was changed to amoxicillin $875 \mathrm{mg}$ and clavulanic acid $125 \mathrm{mg}$ twice a day, along with metronidazole $500 \mathrm{mg}$ three times a day. Microbiological tests for aerobic and anaerobic bacteria taken from pus yielded negative results. Extraction of tooth 16 was performed 11 days after insertion of drains into the abscess. At the same time, a small aggregation of pus located in the same general area was incised and evacuated. Biochemical identification of microorganisms and antimicrobial susceptibility tests, performed using the Vitek 2 system, were also performed. Microbiological testing indicated the presence of strains of Enterococcus faecalis, Lactococcus lactis cremoris, and Streptococcus mitis. Extraction of the tooth that had caused the inflammatory infection, along with the evacuation of the abscess and concomitant antibiotic therapy, resulted in a complete reversal of the pathological process (Figure 3). Two months later, $2 \mathrm{~mL}$ of hyaluronic acid (Princess Volume ${ }^{\circledR}$, Leobendorf, Austria) was injected into the patient's left cheek (Figure 4). She refused to use Q-Med products again. There were no further signs of infection. Biochemical results were within normal limits. No further complications were observed in the year following hyaluronic acid augmentation into her left cheek. The patient underwent a standard medical diagnostic procedure.

\section{Discussion}

According to the literature, hyaluronic acid-based filler injections can be considered safe, but complications may develop as it has been previously reported. Biofilm is a dangerous complication, especially with deeply placed injections. This report highlights the need to carry out careful dental restoration before

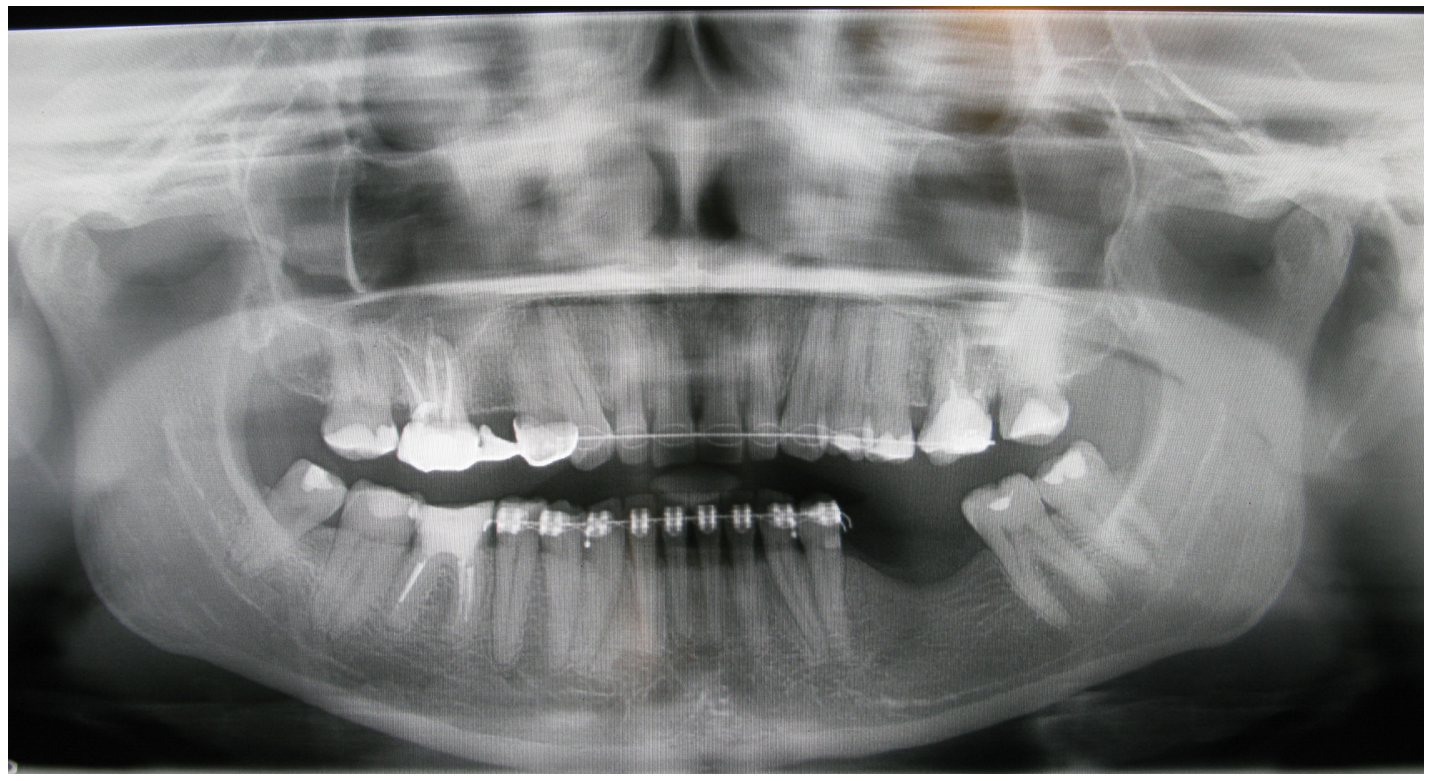

Figure 2 Possible spreading of the bacterial process from improper endodontic treatment of tooth 16. 


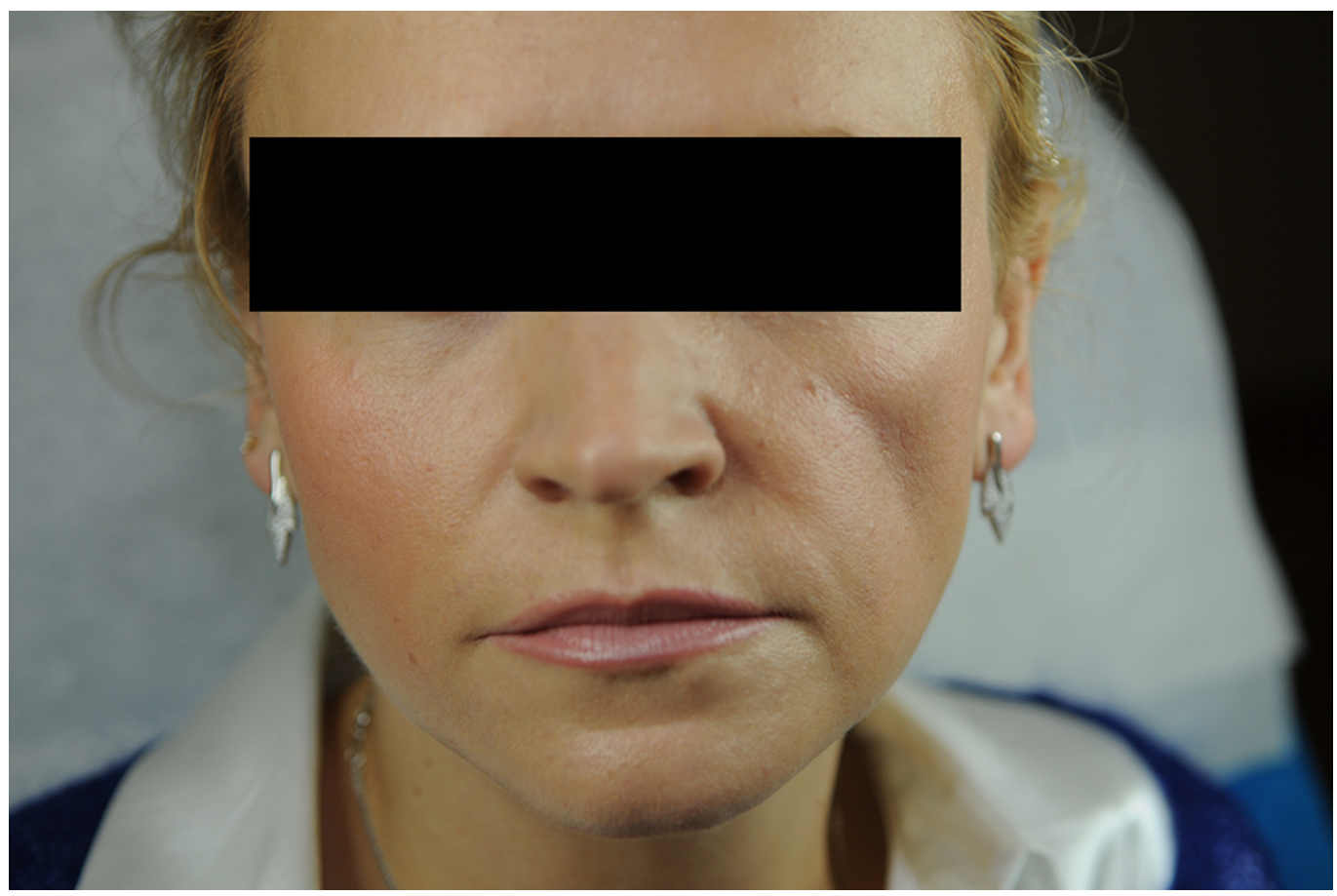

Figure 3 Reversal of pathological process after tooth extraction, evacuation of abscess, and antibiotic therapy.

any aesthetic treatment of the face. It is likely that biofilm can form on all materials that are administered, despite the depth of injection. Since hyaluronic acid is retained within the body for only a short period of time because of the action of hyaluronidase (the tissue half-life of hyaluronic acid ranges from hours to days), the biofilm rapidly biodegrades along with hyaluronic acid. ${ }^{17}$ Therefore, this complication should be considered solely with extended-duration hyaluronic acid material. To avoid such complications in the future, a study of the nature of biofilm specifically created on hyaluronic acid

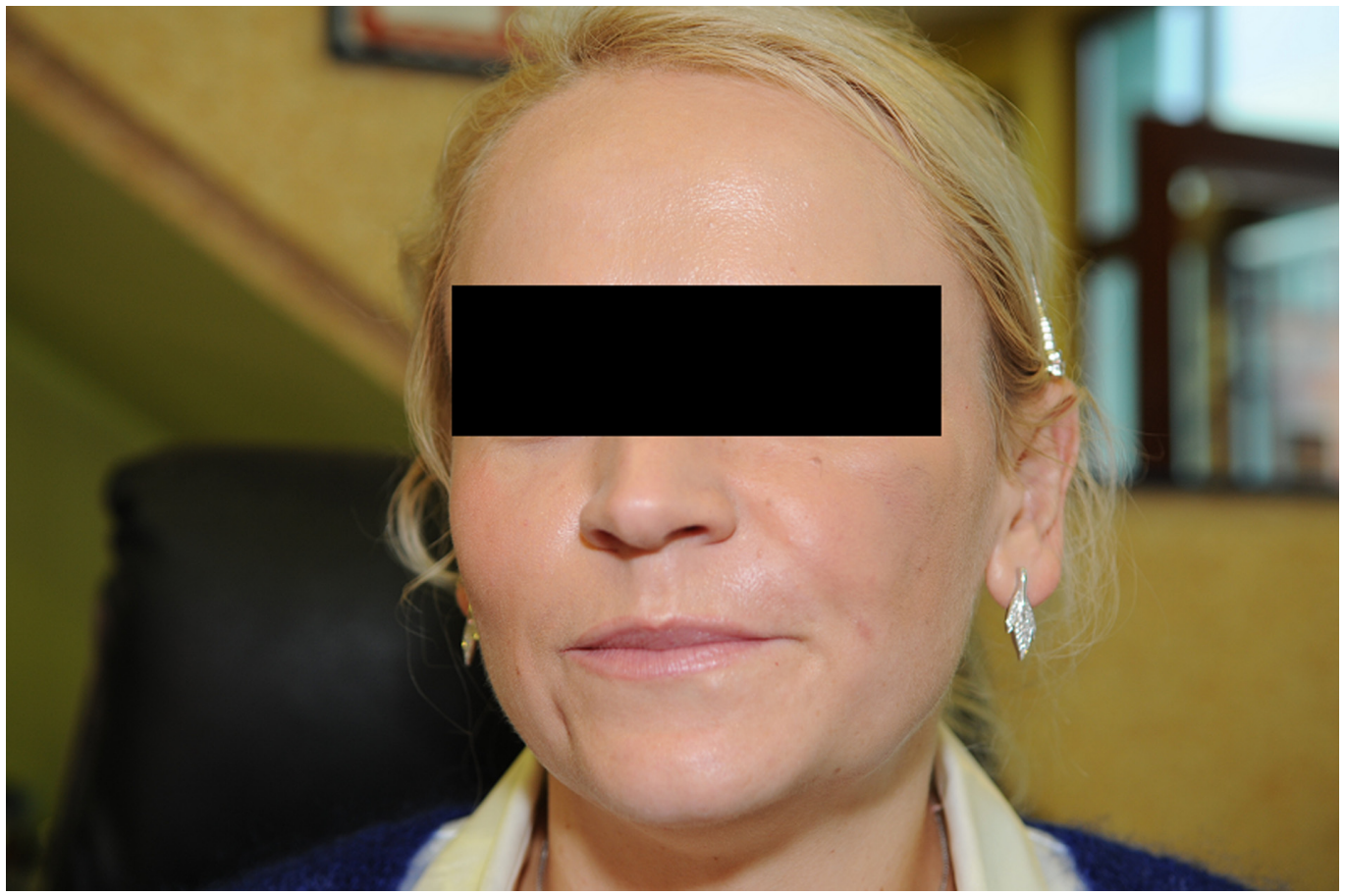

Figure 4 Patient's appearance after injection of $2 \mathrm{~mL}$ of hyaluronic acid into her left cheek. 
should be performed. The injection of fillers can increase the risk of bacterial infections because of improper or inadequate disinfection of the skin, presence of potential pathogens, such as the patients' own microflora, eg, Propionibacterium acnes, Staphylococcus epidermidis, and mycobacteria, decreased immunity, and poor injection technique.

All implanted materials induce the normal body reaction to foreign compounds, but the strength of the reaction varies. ${ }^{18}$ Macrophages, lymphocytes, plasma cells, and foreign body giant cells are usually found. ${ }^{19}$ Bacteria, introduced during hyaluronic acid implantation, can cause untoward reactions mainly attributable to bacterial biofilm formation. In the case of bacteria within biofilm, the resistance of these bacteria to antibiotics is 1000 times greater and treatment of untoward reactions requires a larger dose of antibiotics. ${ }^{18}$ Side effects are quite rare, but occur $0.1 \%-0.5 \%$ of the time, depending on the type of fillers utilized. These reactions can occur immediately, several weeks, months, or even years after injection of the filler. ${ }^{19}$ In the present case, biofilm formation may have occurred. A "sterile abscess" that may have formed as part of a foreign body reaction caused by introduction of hyaluronic acid into the cheek or it may have resulted from an abscess of the infected tooth. Both types of complications are extremely rare in this type of aesthetic procedure. The first complication, ie, the "sterile abscess", is highly unlikely even though negative bacterial cultures were obtained. Abscesses of this type have been reported after administration of hyaluronic acid in aesthetic procedures and in treatment of urinary stress incontinence. ${ }^{20-22}$ The reason for this reaction is not known, but an allergic origin or a foreign body reaction can be hypothesized. ${ }^{23,24}$ Undoubtedly, the physicochemical properties of the preparation and the injection technique may have a decisive impact on the occurrence of such complications. With regard to hyaluronic acid, we must consider actual particle size, shape, hydrophobicity, degree of purification, depth and site of administration, and even the diameter of the needle. ${ }^{18,25}$ Allergies cannot be triggered, because the hyaluronic acid currently in use is not of animal origin, but it is derived from bacteria. Furthermore, in our case, the abscess occurred unilaterally and hyaluronic acid preparation was administered in both cheeks.

Some researchers believe that reported cases of "sterile abscesses", when dealing with a bacterial infection and sterile cultures, stem from the fact that bacteria can be found on the surface of a foreign body (in this case, the particles of the preparation) in the form of biofilm. Within the liquid mass of the abscess there can be so few bacteria that they are virtually undetectable by conventional microbiological method. ${ }^{26}$
A sensitive method for the detection of bacteria is known as fluorescent in situ hybridization which utilizes universal probes, such as peptide nucleic acids and fluorochromelabelled specific DNA sequences found in all bacteria and specific only to bacteria. Common bacteria forming biofilms are not potentially pathogenic and the presence of biofilm does not produce acute symptoms; it can be slow and asymptomatic for months or years, and may activate and exacerbate only in special cases, such as an injury.

The second possibility is that our case was one of maxillary osteomyelitis. In patients without filling material, a cheek abscess is usually an odontogenic infection. In our patient, this possibility, exists primarily because of the pantogram indicating an inflammatory process in the region of the tooth. However, the negative cultures tend to negate this possibility even if the patient had received clindamycin prior to the collection of cultures, and this could explain the negative test results. The causes of periodontal infection are mainly anaerobic flora, and clindamycin is particularly active against anaerobes. From the small reservoir of pus under the tooth, E. faecalis was cultivated, along with other microorganisms. E. faecalis can cause inflammation, especially in combination with other microorganisms, and is intrinsically resistant to clindamycin used in empirical therapy and could be responsible for biofilm and further abscess formation. The infectious nature of this abscess was indicated by test results showing elevated levels of leukocytes, neutrophils, D-dimers, and fibrinogen. With the available test results, it is difficult to determine the primary cause of the described complications. Most likely it was a tooth that was not completely restored to a healthy state endodontically. However, it is quite possible that the cheek abscess would not have formed if the filler had not been injected. The filler acted as a substrate for bacterial biofilm formation which favored the development of the abscess. It is worth mentioning that the filler was injected into both cheeks, but the problem appeared only on the side of the infected tooth. In order to better diagnose this type of complication better, there should have been microbiological samples of the purulent matter prior to administration of any antibiotics. In addition, a biopsy with histopathological analysis would have been a valuable test. Subsequently, one could attempt biomolecular testing, even if beyond routine analytical procedures.

We want to emphasize that the present case report, based on the present diagnostic medical standard, did not prevent biofilm development. Therefore, we propose the introduction of fluorescent in situ hybridization into clinical practice when we are facing a probable biofilm-related infection due to its high reliability. This procedure would allow us to detect 
biofilm and start antibiotic therapy promptly, allowing its immediate resolution. Furthermore, based on the present case report, we suggest that a pantomogram, which is an easy and cost-effective test, should be performed before a cosmetic procedure involving a hyaluronic acid injection.

Due to the widespread use of hyaluronic acid, not only in aesthetic medicine, but also in an effort to achieve more efficient drug delivery, it is of vital importance to determine how biofilm may form when hyaluronic acid-based fillers are used. Therefore, it is important to analyze this and other case reports, as well as undertake larger clinical studies to determine if hyaluronic acid is involved in the formation of biofilm. It is also possible that, in the near future, studies focusing on changes in the hyaluronic acid molecule may help to limit the complications associated with hyaluronic acid injection, making hyaluronic acid-based procedures safer.

\section{Disclosure}

The authors report no conflicts of interest in this work.

\section{References}

1. Beasley KL, Weiss MA, Weiss RA. Hyaluronic acid fillers: a comprehensive review. Facial Plast Surg. 2009;25(2):86-94.

2. Iannitti T, Lodi D, Palmieri B. Intra-articular injections for the treatment of osteoarthritis: focus on the clinical use of hyaluronic acid. Drugs $R D$. 2011;11(1):13-27.

3. Weinberg MJ, Solish N. Complications of hyaluronic acid fillers. Facial Plast Surg. 2009;25:324-328.

4. Kassir R, Kolluru A, Kassir M. Extensive necrosis after injection of hyaluronic acid filler: case report and review of the literature. J Cosmet Dermatol. 2011;10(3):224-231.

5. Palmieri B, Monaco M, Capone $\mathrm{S}$. Complications caused by using facial fillers. Dermatological Experience. 2010;2 Suppl 2:1-11.

6. Christensen LH. Host tissue interaction, fate, and risks of degradable and nondegradable gel fillers. Dermatol Surg. 2009;35 Suppl 2: $1612-1619$.

7. Alijotas-Reig J, Miro-Mur F, Planells-Romeu I, Garcia-Aranda N, Garcia-Gimenez V, Vilardell-Tarres M. Are bacterial growth and/or chemotaxis increased by filler injections? Implications for the pathogenesis and treatment of filler-related granulomas. Dermatology. 2010;221(4):356-364.

8. Platt VM, Szoka FC. Anticancer therapeutics: targeting macromolecules and nanocarriers to hyaluronan or $\mathrm{CD} 44$, a hyaluronan receptor. $\mathrm{Mol}$ Pharm. 2008;5(4):474-486.

9. Yamada J, Kitayama J, Tsuno NH. Intra-peritoneal administration of paclitaxel with non-animal stabilized hyaluronic acid as a vehicle a new strategy against peritoneal dissemination of gastric cancer. Cancer Lett. 2008;272:307-115.

International Journal of Nanomedicine

\section{Publish your work in this journal}

The International Journal of Nanomedicine is an international, peerreviewed journal focusing on the application of nanotechnology in diagnostics, therapeutics, and drug delivery systems throughout the biomedical field. This journal is indexed on PubMed Central, MedLine, CAS, SciSearch ${ }^{\circledR}$, Current Contents ${ }^{\circledR} /$ Clinical Medicine,
10. Coradini D, Pellizzaro C, Miglierini G, Daidone MG, Perbellini A. Hyaluronic acid as drug delivery for sodium butyrate: improvement of the anti-proliferative activity on a breast-cancer cell line. Int $J$ Cancer. 1999;81(3):411-416.

11. Kumar A, Pellizzaro C, Miglierini G, Daidone MG, Perbellini A. Development of hyaluronic acid- $\mathrm{Fe}_{2} \mathrm{O}_{3}$ hybrid magnetic nanoparticles for targeted delivery of peptides. Nanomedicine. 2007;3(2):132-137.

12. Wadhwa S, Paliwal R, Paliwal SR, Vyas SP. Hyaluronic acid modified chitosan nanoparticles for effective management of glaucoma: development, characterization, and evaluation. J Drug Target. 2010; 18(4):292-302.

13. Alijotas-Reig J, Hindie M, Kandhaya-Pillai R, Miro-Mur F. Bioengineered hyaluronic acid elicited a nonantigenic $\mathrm{T}$ cell activation: implications from cosmetic medicine and surgery to nanomedicine. $J$ Biomed Mater Res A. 2010;95(1):180-190.

14. Sanchez O, Rodriguez-Sureda V, Dominguez C. Study of biomaterialinduced macrophage activation, cell-mediated immune response and molecular oxidative damage in patients with dermal bioimplants. Immunobiology. 2012;217(1):44-53.

15. Cermelli C, Cuoghi A, Scuri M, et al. In vitro evaluation of antiviral and virucidal activity of a high molecular weight hyaluronic acid. Virol J. 2011;8:141.

16. Ardizzoni A, Neglia RG, Baschieri MC, et al. Influence of hyaluronic acid on bacterial and fungal species, including clinically relevant opportunistic pathogens. J Mater Sci Mater Med. 2011;22(10):2329-2338.

17. Laurent TC, Fraser JR. The properties and turnover of hyaluronan. Ciba Found Symp. 1986;124:9-29.

18. Narins RS, Coleman WP, Glogau RG. Recommendations and treatment options for nodules and other filler complications. Dermatol Surg. 2009;35 Suppl 2:1667-1671.

19. Christensen L, Breiting V, Janssen M, Vuust J, Hogdall E. Adverse reactions to injectable soft tissue permanent fillers. Aesthetic Plast Surg. 2005;29(1):34-48.

20. Sage RJ, Chaffins ML, Kouba DJ. Granulomatous foreign body reaction to hyaluronic acid: report of a case after melolabial fold augmentation and review of management. Dermatol Surg. 2009;35 Suppl 2:1696-1700.

21. Hilton P. Urethrovaginal fistula associated with 'sterile abscess' formation following periurethral injection of dextranomer/hyaluronic acid co-polymer (Zuidex) for the treatment of stress urinary incontinence a case report. BJOG. 2009;116(11):1527-1530.

22. Sahai A, Thomas M, Nedas T, Larner T, Niekrash R, Hammadeh MY. Periurethral non-animal stabilized hyaluronic acid/dextranomer injections: efficacy and formation of granuloma/sterile abscess. Urology. 2009;74:486-488.

23. Sidwell RU, Dhillon AP, Butler PE, Rustin MH. Localized granulomatous reaction to a semi-permanent hyaluronic acid and acrylic hydrogel cosmetic filler. Clin Exp Dermatol. 2004;29:630-632.

24. Mamelak AJ, Katz TM, Goldberg LH, Graves JJ, Kaye VN, Friedman PM. Foreign body reaction to hyaluronic acid filler injection: in search of an etiology. Dermatol Surg. 2009;35 Supp1 2:1701-1703.

25. Bjarnsholt T, Tolker-Nielsen T, Givskov M, Janssen M, Christensen LH. Detection of bacteria by fluorescence in situ hybridization in culturenegative soft tissue filler lesions. Dermatol Surg. 2009;35 Suppl 2: $1620-1624$.

26. Glogau RG, Kane MA. Effect of injection techniques on the rate of local adverse events in patients implanted with nonanimal hyaluronic acid gel dermal fillers. Dermatol Surg. 2008;34 Suppl 1:S105-S109.

\section{Dovepress}

Journal Citation Reports/Science Edition, EMBase, Scopus and the Elsevier Bibliographic databases. The manuscript management system is completely online and includes a very quick and fair peer-review system, which is all easy to use. Visit http://www.dovepress.com/ testimonials.php to read real quotes from published authors. 